\title{
Responses of Rhizospheric Microbial Communities of Native and Alien Plant Species to Cuscuta Parasitism
}

\author{
Caroline Brunel $^{1}$ (D) Y Yang Beifen ${ }^{1} \cdot$ Robin Pouteau $^{1}$ (D) Junmin Li ${ }^{1} \cdot$ Mark van Kleunen $^{1,2}$ (D)
}

\begin{abstract}
Parasitic plants have major impacts on host fitness. In the case of species of the holoparasitic Cuscuta genus, these impacts were shown to be particularly strong in some invasive alien plants, which has raised interest in the underlying mechanism. We hypothesized that Cuscuta parasitization may exert strong influence in shaping the diversity patterns in the host rhizosphere microbiome and that this may vary between native (coevolved) and alien (non-coevolved) plants. Here, we report on a field study exploring the effect of parasitization by Cuscuta australis on the rhizosphere microbiota (16S and ITS rDNA) of four plant species sharing and three plant species not sharing the parasite's native range. Despite a predominant role of the host species in shaping the rhizosphere microbiota, the role of host origin and of parasitization still appeared important in structuring microbial communities and their associated functions. Bacterial communities were more strongly influenced than fungi by the native range of the host plant, while fungi were slightly more affected than bacteria by parasitization. About $7 \%$ of bacterial phylotypes and $11 \%$ of fungal phylotypes were sensitive to Cuscuta parasitization. Parasitization also reduced the abundance of arbuscular mycorrhizal fungi by ca. $18 \%$ and of several genes related to plant growth promoting functions (e.g., nitrogen metabolism and quorum sensing). Both fungi and bacteria differentially responded to host parasitization depending on host origin, and the extent of these shifts suggests that they may have more dramatic consequences for alien than for native plants.
\end{abstract}

Keywords Plant-stem parasite $\cdot$ Rhizosphere $\cdot$ Invasive and native plant species $\cdot$ Structure and composition of microbial communities

\section{Introduction}

Parasitic plants are keystone species that can be found in all terrestrial biomes. By connecting to the vascular bundles of their hosts via specialized organs called haustoria, they acquire photoassimilates, solutes, metabolites, and water. Parasitization has major impacts on host fitness, and this changes the competitive balance between host and non-host species [1, 2], alters ecosystem structure, and causes strong

Junmin Li

lijmtzc@126.com

1 Zhejiang Provincial Key Laboratory of Plant Evolutionary Ecology and Conservation, Taizhou University, Taizhou 318000, China

2 Department of Biology, University of Konstanz, Universitätsstrasse 10, D-78457 Konstanz, Germany damage to both native biota and human societies [3-5]. Although some host plants are passively resistant (e.g., have physical barriers, like in monocotyledons) or actively resistant (e.g., show hyper-sensitive responses, like in Solanum lycopersicum) to plant parasitization, most plants do not possess any effective defense mechanisms. Parasitization induces reallocation of resources from the host to the parasite, which leads to changes in host allometry and architecture [6]. This affects water and nutrient balances, and reduces host photosynthesis, respiration, and root exudation [7]. Parasitism thus gradually weakens and limits host growth [8], and, in the most extreme cases, results in host death [9]. To survive as long as possible and be able to reproduce, host plants have to adjust their physiological activity in response to parasitization. This might involve an adjustment of the balance between growth and defense.

Such plasticity can be modulated by the host's associated microbiota. Rhizosphere microbiota supply plants with nutrients [10], protect them against pathogens [11], stimulate their growth by producing phytohormones, and improve plant resistance or tolerance to stress, such as variation in temperature, 
drought, and salinity [12]. Plants and microorganisms thus function in tandem, and plants have the ability to manipulate bacteria and their activities in order to enhance those interactions to their own benefit [13]. Microbial recruitment by a plant is mostly manipulated via the plant's root exudates [14-16]. However, the reallocation of resources toward the parasitic plant has been shown to severely affect both carbon (C) and nitrogen $(\mathrm{N})$ fluxes between the root and the rhizosphere of the host plant [7]. Previous studies estimated that parasitization strongly inhibits root respiration [17] and induces simultaneously an inhibition of $\mathrm{N}$ assimilation in the host roots and an increase in N uptake [18]. It is also likely that the chemical composition of root exudates shifts with parasitism, although experimental evidence for this is lacking. The change in the rhizosphere environment (inputs of water, $\mathrm{C}$, nutrients, signaling molecules) raises the intriguing possibility that parasitization can have important consequences on rhizosphere microbiota. Unfortunately, most of the experiments studying the host/parasitic plant complex have been carried out in artificial conditions in which the impact of parasitization on root exudation and on the rhizosphere microbiome has rarely been taken into account [19].

Interest in the stem holoparasite (or obligate parasite) Cuscuta has grown when C. australis, C. campestris, and C. chinensis were discovered parasitizing and restraining the invasive alien vine Mikania micrantha in the southern part of China, which pointed out their potential as control agents [20, 21]. On Neilingding Island (southern China), Yu et al. [22] found a higher parasitization rate on Mikania than on other species, possibly because of a higher tissue nutrient content. Similarly, the native generalist parasite Cassytha pubescens was found to have a greater effect on the physiology of a novel alien host than on a native host with which it co-occurs [23]. Invasive alien plants and plant parasites both have high fitness abilities, and part of the explanation could derive from their functional capacities that could lead them to share similar niches. In a country-scale study based in Hungary, Baráth [24] revealed that plant species occupying nitrogen-rich habitats were the preferred hosts for Cuscuta europaea. Concomitantly, Liao et al. [25] found in a meta-analysis that sites invaded by alien plants were associated with $83 \%$ more above-ground net primary productivity, $17 \%$ higher soil nitrate concentrations, and $53 \%$ higher net nitrification rates across ecosystems as compared with non-invaded sites.

Here, we report on a field study exploring the effect of parasitization by Cuscuta australis on the rhizosphere microbiome of four plant species sharing and three plant species not sharing the parasite's native range. We hypothesized that Cuscuta parasitization exerts a strong influence on shaping the diversity patterns in the host rhizosphere microbiome, that parasitization particularly promotes plant-growth promoting bacteria and arbuscular mycorrhizal fungi (AMF), and that these effects may vary between native (coevolved) and alien (non-coevolved) plants. Based on 16S and ITS rDNA investigation, we examined parasitization effects on diversity and composition of both bacterial and fungal communities of the host plant's rhizosphere. We addressed the following specific questions: (i) Can parasitization induce a shift in host root microbiome and, if so, (ii) are these shifts characterized by an increase in plant growth promoting taxa and functional groups? (iii) Are the root microbiomes of native and alien invasive plants similarly affected?

\section{Methods}

\section{Study Site and Species}

We conducted our study in the National Sanjiang Wetland

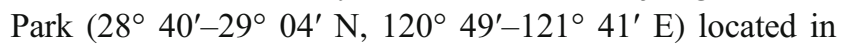
Linhai City, Zhejiang Province, southeastern China. The climate of the region is subtropical, with a mean annual precipitation of c. $2000 \mathrm{~mm}$ and a mean annual temperature of $16.5^{\circ} \mathrm{C}$ (data extracted from the Chelsa database [26]). In this region, a wide range of herb and shrub species are parasitized by the native annual holoparasite Cuscuta australis (Convolvulaceae; hereafter Cuscuta) so that it is considered a noxious agricultural weed [27].

Field surveys have shown that Cuscuta spp. can infect a wide range of hosts (plants in the Asteraceae, Fabaceae, and other families), including the invasive alien Mikania micrantha, Ipomoea cairica, Wedelia trilobata, Alternanthera philoxeroides, and Bidens pilosa [27, 28]. For our study, we selected seven host plant species in the National Sanjiang Wetland Park (Table 1). As we aimed to test whether the root microbiome of native and alien species are differently affected by Cuscuta parasitization, we selected four native and three alien species. The latter are categorized as invasive in China [29] and are native to the Americas so that they do not have long coevolutionary histories with the parasite.

\section{Soil Sampling}

On June 25, 2016, rhizosphere soils of plants of the seven host species parasitized by $C$. australis and of non-parasitized plants of those species were sampled. The distance between sampled plants of the same species ranged from 200 to $900 \mathrm{~m}$. In total, 42 plants $(7$ species $\times 2$ parasitization levels $\times 3$ replicates) were carefully uprooted from the substrate and the loosely adhering soil was gently removed from the roots by shaking. The remaining adhering rhizosphere soils were collected and placed in sterilized polypropylene bags. Soil samples were immediately cooled to $4{ }^{\circ} \mathrm{C}$ and transported to the laboratory. After sieving to remove plant material and small rocks, the soil was used for microbial analysis. 
Table 1 Family, status, and native range of the parasite and the seven host plant species used in the study

\begin{tabular}{|c|c|c|c|}
\hline Plant species & Family & Status & Native range \\
\hline \multicolumn{4}{|l|}{ Parasite } \\
\hline Cuscuta australis & Convolvulaceae & Native & $\begin{array}{l}\text { Africa, Asia (temperate and tropical), } \\
\text { Australasia and Europe }\end{array}$ \\
\hline \multicolumn{4}{|l|}{ Host } \\
\hline Alternanthera philoxeroides & Amaranthaceae & Alien & Southern America \\
\hline Artemisia аппиа & Asteraceae & Native & Asia (temperate) and Europe \\
\hline Bidens pilosa & Asteraceae & Alien & Northern and southern America \\
\hline Conyza canadensis & Asteraceae & Alien & Northern and central America \\
\hline Humulus japonicas & Moraceae & Native & Asia (temperate and tropical) \\
\hline Kalimeris indica & Asteraceae & Native & Southern and eastern Asia \\
\hline Mosla scabra & Labiatae & Native & Asia (temperate and tropical) \\
\hline
\end{tabular}

\section{DNA Extraction, PCR Amplification, and Sequencing}

Soil genomic DNA was extracted from the soil samples, using a Fast DNA SPIN Kit for soil (MP Biomedicals, Santa Ana, $\mathrm{CA}$ ), according to the manufacturer's protocol. DNA was dissolved in TE buffer and spectrophotometrically quantified with a NanoDrop 2000 (Thermo Fisher Scientific, San Diego, CA, USA). PCR amplifications were conducted in a Roche LightCycler 96 system (Roche Molecular Systems, Inc. Pleasanton, CA, USA) with bacterial primer pairs (forward primer: 5'-CCTACGGGNGGCWGCAG-3'; reverse primer: 5'-GACTACHVGGGTATCTAATCC-3') that amplify the V3-V4 region of the 16S rDNA gene [30] and fungal primer pairs (forward primer: 5'-GCATCGATGAAGAA CGCAGC-3'; reverse primer: 5'-TCCTCCGCTTATTG ATATGC- $3^{\prime}$ ) that amplify the ITS2 region of the fungal rDNA gene [31]. Illumina adapter overhang nucleotide sequences were added to gene-specific sequences (primer 1: 5'-TCGTCGGCAGCGTCAGATGTGTATAAGAGACAG3'; primer 2: 5'-GTCTCGTGG GCTCGGAGATGTGT ATAAGAGACAG-3'). Amplicon PCR of both bacteria and fungi was performed to amplify the template out of a DNA sample using specific primers with attached overhang adapters for the region of interest. The amplification was conducted in $25 \mu 1$ reactions under the following conditions: initial denaturation at $95^{\circ} \mathrm{C}$ for $3 \mathrm{~min}$, followed by 30 cycles at $95{ }^{\circ} \mathrm{C}$ for $30 \mathrm{~s}, 55{ }^{\circ} \mathrm{C}$ for $30 \mathrm{~s}, 72{ }^{\circ} \mathrm{C}$ for $45 \mathrm{~s}$, and a final extension step of $5 \mathrm{~min}$ at $72{ }^{\circ} \mathrm{C}$. Amplicons were cleaned using AMPure XP beads, then dual indices and Illumina sequencing adapters were attached using the Nextera XT Index Kit. The library was cleaned with AMPure XP beads and quantified using a fluorometric quantification method on an Agilent Technologies 2100 Bioanalyzer tracer. Libraries were normalized, and up to 96 libraries were pooled for one Miseq run. All experiments were conducted according to the official protocols published on the Illumina website (https://support. illumina.coml). Amplicon sequencing was performed on the
Illumina Miseq Benchtop sequencer (Illumina Inc. San Diego, CA, USA) from Jingbai Biotechnology Co. Ltd. in Hangzhou, China. Three replicates were used for this analysis. The nucleotide sequence data are available in the GenBank database under the project accession number PRJNA530112.

\section{Data Processing}

Raw sequences were processed using a custom script from the DADA2 pipeline [32], which is designed to resolve exact biological sequences (Amplicon Sequence Variants [ASVs] or phylotypes) from Illumina sequence data and does not involve sequence clustering [33]. Raw sequences were first demultiplexed by comparing index reads with a key, and paired sequences were trimmed to uniform lengths. Sequences were dereplicated, and the unique sequence pairs were denoised using the "dada" function. Primers and adapters were screened and removed using a custom script with "cutadapt" [34]. Next, paired-end sequences were merged, and chimeras were removed. Taxonomy assignments were determined against derivative reformatting of the UNITE [35] and the SILVA [36] taxonomic databases for fungi and bacteria, respectively. The average library size for each group was similar, and therefore rarefication did not increase the false discovery rate [37]. Then, to account for differences in sequencing depths, samples were rarefied to 4200 and 1200 for bacteria and fungi, respectively. Putative fungal functional groups were identified using FUNGuild [38], and bacterial gene function prediction was performed using the tax 4 fun function [39] against the KEGG database from the metagenomics package.

\section{Data Analysis}

All bioinformatic and statistical analyses were performed using $\mathrm{R}$ version 3.5.0 [40]. As measures of alpha diversity, we calculated the Shannon and Simpson indexes, and 
analyzed them with linear mixed models (function "Imer" of the package "lme4" [41]) to test whether they were significantly affected by parasitization ("parasitized" or "non-parasitized"), host origin ("alien" or "native"), and their interaction. To account for non-independence of samples collected from the same host species, we included host species as a random effect in the model. As a measure of beta diversity, we calculated Bray-Curtis dissimilarities using relative abundances of the reads. Permutational analysis of variance (PERMANOVA), implemented in the "adonis" function of the "vegan" package [42], was used to test for significant effects of parasitization ("parasitized" or "non-parasitized"), host origin ("alien" or "native"), and their interaction on rhizosphere community composition. We included host species as random effect in the model. The effects of parasitization and host origin on rhizospheric microbial taxa at the host-species level were addressed using negative binomial mixed models designed to deal with zero inflation (function "glmm.zinb", available in the R package "NBZIMM" [43]) and by setting host species as a random effect. For the analysis of bacterial functional features (KEGG Orthologs [KOs] [44]), only those contigs likely to be relevant for plant growth promotion (i.e., nitrogen metabolism, tryptophan metabolism, quorum sensing, signal transduction, biodegradation and metabolism of xenobiotics, metabolism of terpenoids and polyketides, metabolism of cofactors and vitamins, membrane transport, biosynthesis of other secondary metabolites) were investigated individually. We also calculated the putative abundance of genes involved in each reaction of the soil $\mathrm{N}$ cycle, i.e., anaerobic ammonium oxidation, assimilatory nitrate reduction, denitrification, dissimilatory nitrate reduction, nitrification, and nitrogen fixation nitrification by summing up the hits abundance of the KOs involved in each of these reactions as defined in the KEGG database. The effects of parasitization and host origin on KOs' estimated abundances were tested using negative binomial mixed models (function "glmm.nb" of the package "NBZIMM") and by setting host species as random effect. A similar approach was applied for reads abundance of phyla and fungal groups. False discovery rate corrections [45] were used to account for multiple comparisons. Differences between groups were further determined using the "emmeans" function of the "lsmeans" package on the fitted models [46]. We identified particular soil taxa that were associated with host origin or parasitization levels using indicator analyses [47] with the function "multipatt" implemented in the "indicspecies" package [48]. The algorithm determines both fidelity to a group (here parasitization level or origin of the host) and consistency (i.e., consistent occurrence among plants within the groups) and provides a statistic (IndVal) and the respective $p$ value, appropriate placement, and hierarchical level for the species. Levels of significance were set to $p \leq 0.05$. All graphical presentations have been realized with the "ggplot" function of the "ggplot2" package [49].

\section{Results}

\section{Taxonomic Profiles of the Rhizospheric Microbiota}

A total of $179,29816 \mathrm{~S}$ reads ( $\sim 7270$ phylotypes) and 49,200 ITS reads ( $\sim 1280$ phylotypes), belonging to 34 bacterial and 11 fungal phyla, were detected. Bacteria were primarily composed of Proteobacteria (38\% of $16 \mathrm{~S}$ sequences reads; Supplementary Fig.1A), Acidobacteria (17\%), and Planctomycetes (12\%). Fungi were primarily composed of Ascomycota (37\% of ITS sequence reads, on average; Supplementary Fig.1B), Basidiomycota (19\%), and Mortierellomycota (9\%).

The alpha diversity of the rhizosphere microbiome was not significantly affected by parasitization and host origin (Supplementary Table $1 \mathrm{~A}$ and B). Host plant species explained a large part of the variation in the overall composition of soil bacterial (PERMANOVA, $r^{2}=0.381 ; p<0.001$, Fig. 1a) and fungal communities (PERMANOVA, $r^{2}=$ $0.341 ; p<0.001$, Fig. 1b), indicating that rhizosphere microbiomes tended to be strongly associated with particular host species. PERMANOVA additionally revealed a significant effect of host origin on the composition of the rhizosphere microbiome $\left(r^{2}=0.081, p=0.018\right.$ for bacteria; $r^{2}=0.066$, $p=0.009$ for fungi) and a smaller but still significant effect of parasitization $\left(r^{2}=0.025, p=0.012\right.$ for bacteria; $r^{2}=0.029$, $p=0.002$ for fungi). Moreover, the fungal rhizosphere microbiota of native and alien plants responded differently to parasitization (significant interaction effect, PERMANOVA, $r^{2}=$ 0.027, $p=0.015$, Fig. 1d).

\section{Effect of Parasitization on the Composition of the Rhizosphere Microbiome}

Differential abundance testing showed that 521 out of 6802 tested bacterial phylotypes ( $7.6 \%$ of the phylotypes accounting for $14.0 \%$ of the total $16 \mathrm{~S}$ reads, Fig. $2 \mathrm{a})$ and 136 out of 1216 tested fungal taxa $(\sim 11.2 \%$ of the phylotypes accounting for $37.2 \%$ of the total ITS reads, Fig. 2b) were sensitive to host parasitization. Moreover, indicator analysis identified three bacterial and two fungal phylotypes as strongly associated with non-parasitized plants, and one bacterial and three fungal taxa as strongly associated with parasitized plants (Fig. 2c).

Most bacterial and fungal phyla did not show strong prevalence differences between parasitized and non-parasitized plants, except Verrucomicrobia that were less abundant in the rhizosphere of parasitized plants $\left(F=11.39, p=0.002, p_{\text {adj }}=0.03\right.$, Supplementary Table 2B) and SHA-109, which by contrast were 
a

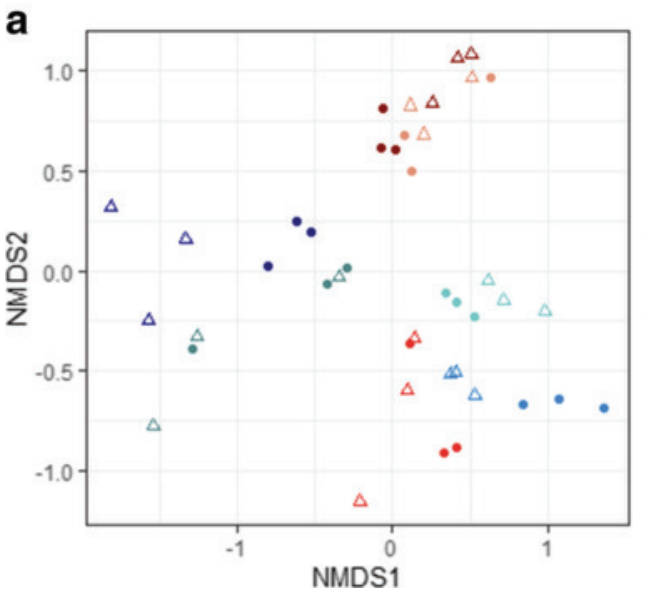

Fig. 1 Non-metric dimensional scaling (NMDS) of bacterial (a) and fungal communities (b) based on Bray-Curtis dissimilarity distances. The colors of the symbols refer to the different host plant species: red and blue tones correspond to alien and native plants, respectively, filled and

more abundant in the rhizosphere of parasitized plants $(F=$ 15.81, $p<0.001, p_{\text {adj }}=0.01$, Supplementary Table 2B). However, phylotypes from the Planctomycetes bacterial phylum appeared particularly sensitive to host parasitization, as they were more prevalent among enriched $(+3.3 \%)$ and reduced $(+5.2 \%)$ taxa than among taxa that did not respond. Parasitization was not favorable to Verrucomicrobia taxa $(-3.4 \%$ of enriched b

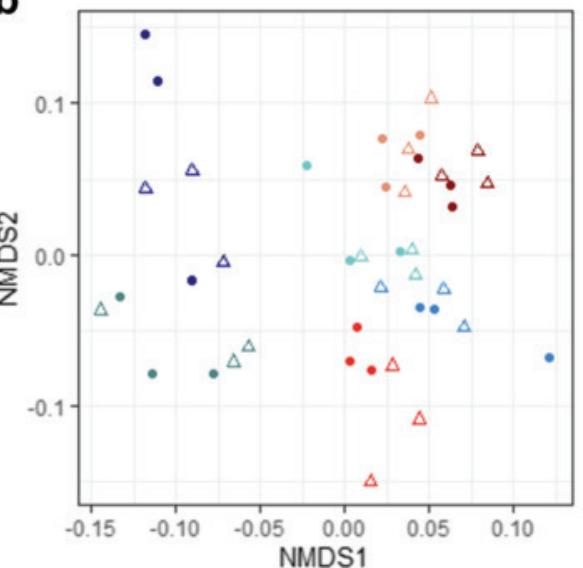

Plant species

- A. philoxeroides

- B. pilosa

- C. canadensis

A. annua

H. japonicus

$K$. indica

M. scabra

Parasitization

- non-parasitized

$\triangle$ parasitized

open symbols correspond to non-parasitized and parasitized plants, respectively. The stress values of the NMDS plot are respectively 0.0921 for Fig. 1a and 0.2032 for Fig. 1b

phylotypes) and promoted Acidobacteria taxa $(+2.7 \%$ of enriched phylotypes). Concerning fungi, phylotypes from the Glomeromycota and Basidiomycota phyla were less sensitive to host parasitization, as they were relatively less prevalent among both enriched and reduced phylotypes in comparison with the those that did not respond $(-6.2 \%$ and $-4.0 \%$ of enriched phylotypes and $-4.7 \%$ and $-2.5 \%$ of reduced

a

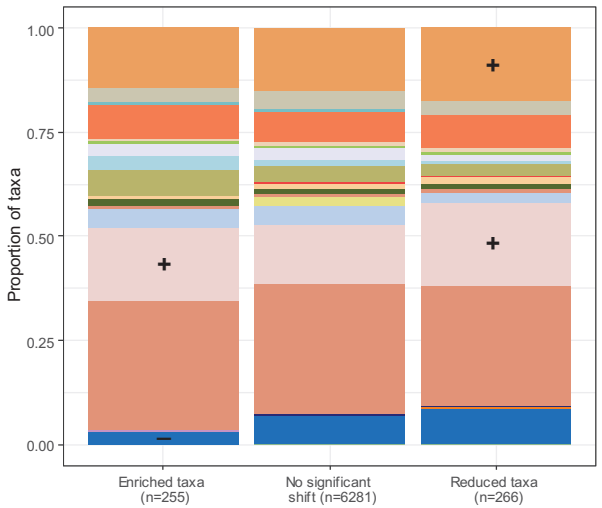

b

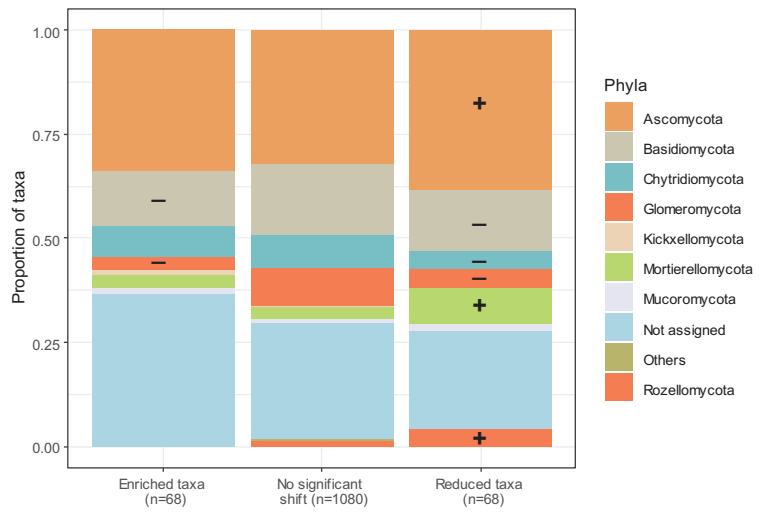

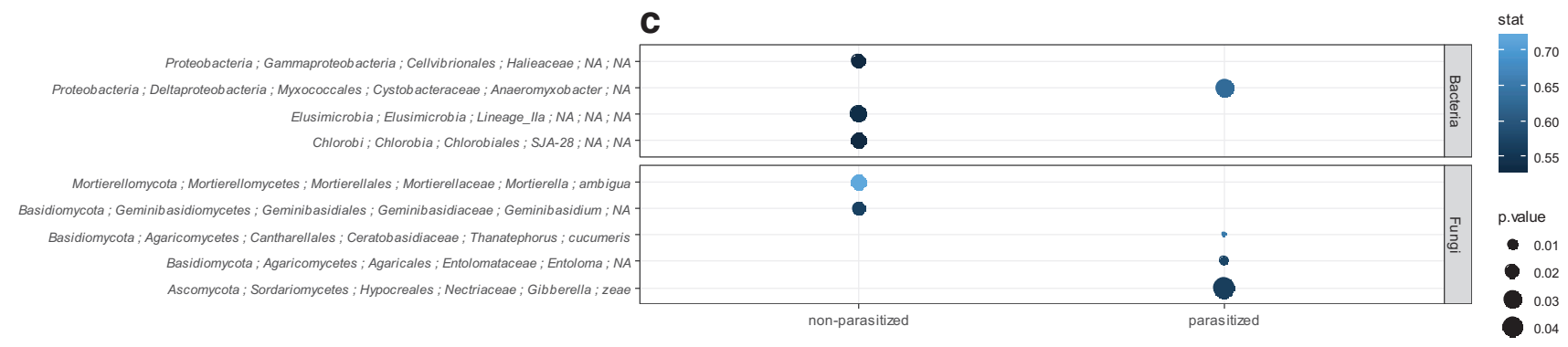

Fig. 2 Sensitivity of microbial taxa to host parasitization. Proportion of taxa significantly enriched, reduced, or not affected by Cuscuta infection for bacteria (a) and fungi (b). Colors refer to the different phyla and phyla whose increase or decrease in the proportion of phylotypes exceeds $2.5 \%$ compared with the insensitive taxa are annotated by $(+)$ and $(-)$, respectively. Phyla that were not found to be sensitive are annotated as "others". (c) Indicator taxa of the rhizosphere microbiome for parasitized or non-parasitized host plants. Point size indicates the strength with which taxa are indicators ( $p$ value). Point colors represent the Indval statistic. Only indicator taxa with Indval $\geq 0.5$ and $p \leq 0.05$ (after Benjamini and Hochberg (1995) post hoc correction) are shown 
phylotypes, respectively). The Ascomycota, Mortierellomycota, and Rozellomycota fungal phyla appeared particularly sensitive to host parasitization, as they were relatively more prevalent among reduced taxa $(+6.1 \%,+5.9 \%$, and $+2.9 \%$ of reduced phylotypes, respectively) than among taxa that did not respond. Conversely, fewer Chytridiomycota phylotypes were affected by parasitization ( $-3.2 \%$ of reduced taxa). A total of 28 out of the 31 identified chytrid phylotypes (on a total of 95 Chytridiomycota phylotypes identified at the phylum level) were recorded as plant pathogens in the FUNGuild database. Fungal lifestyles (e.g., AMF, endophytes, and plant pathogens) have been assigned to the identified phylotypes, which represent $51.2 \%$ of the phylotypes and about $53.0 \%$ of the total abundance. It appeared that plant parasitization neither affected total prevalence of pathogens nor of endophytes, but significantly reduced the abundance of AMF $(F=4.39, p=0.04$, Supplementary Fig. 4) by ca. $18 \%$. It is important to mention here that the used primer pair is known to be limited in its ability to recover AMF [50], that most AMF taxa have not been cultured or fully described [51], and that those biases likely introduced a degree of uncertainty to our results. However, as the identified AMF represent a significant part of the fungi that were recovered in our study, those results are still important to mention.

\section{Effect of Host Origin on the Composition of the Rhizosphere Microbiome}

Indicator analysis identified an important number of specific associations between certain microbial taxa and the host origin (Supplementary Fig. 2). Particularly, 37 bacterial (mainly Proteobacteria and Actinobacteria) and 12 fungal phylotypes (mainly Basidiomycota, Mortierellomycota and Rozellomycota) were strongly associated with alien plants, whereas 23 bacterial (mainly Acidobacteria and Chloroflexi) and 19 fungal phylotypes (mainly Glomeromycota and Ascomycota) were strongly associated with native plants. Among the fungal phylotypes associated with either alien or native plant species, no preferential association with particular trophic modes was distinguishable (both equally involved saprotrophs, symbiotrophs, and pathotrophs).

Although certain bacterial and fungal phyla appeared to be more strongly associated with either native or alien plants (Supplementary Fig. 3), only the differences in abundance of Rozellomycota were marginally greater in the rhizosphere of alien plants $\left(F=21.01, p=0.006, p_{\text {adj }}=0.071\right.$, Supplementary Table 2A). However, the ratio of Proteobacteria to Acidobacteria, which is indicative of the nutrient status of the soil, was significantly lower in the rhizosphere of native plants ( $F=9.98, p=0.025$, Supplementary Fig. 3).

Differential abundance testing revealed that 17 out of 6802 tested bacterial taxa (not assigned at the species level) and 2 out of 1216 tested fungal taxa differed significantly in response to parasitization between the native and alien hosts.
The two identified fungal taxa are Basidiomycota. The first, which was less abundant with parasitization in the rhizosphere of alien plants and was not affected in the rhizosphere of native plants, belongs to the plant saprotroph genus Coprinopsis. The second phylotype, whose abundance was upregulated by parasitization for aliens and downregulated for natives, belongs to the plant pathogen family Ceratobasidiaceae [52]. Furthermore, separate PERMANOVA analyses of alien and native plants revealed a significant difference in rhizosphere fungal composition between parasitized and non-parasitized native plants $(F=1.15$, $\left.r^{2}=0.051, p=0.02\right)$, whereas it was marginally nonsignificant for aliens $\left(F=1.30, r^{2}=0.075, p=0.052\right)$.

\section{The Functional Composition of the Rhizosphere Bacterial Communities}

Based on sequences from protein-encoding genes of each bacterial community, a total of $3620 \mathrm{KO}$ tags were obtained, of which 1348 (37\%) could be assigned to one or several functional categories. An NMDS plot based on those KOs showed that plant species had a strong effect on the functional composition of the bacterial microbiome (PERMANOVA, $r^{2}=$ 0.545, $p<0.001$, Supplementary Fig. 5). Parasitization and origin of the host plant, however, explained only small, marginally non-significant proportions of the variation (PERMANOVA, parasitization; $r^{2}=0.023, p=0.057$, origin; $r^{2}=0.092, p=0.066$, Supplementary Fig. 5), and their interaction was not significant $\left(r^{2}=0.016, p=0.267\right)$. A total of 26 KOs $(\sim 0.7 \%)$ were unique to the native host plants, and only one was unique to the alien plants. Furthermore, nine KOs ( $0.2 \%)$ were unique to parasitized plants and $14(\sim 0.4 \%)$ were unique to non-parasitized plants.

\section{Effect of Plant Parasitization on the Functional Composition of Rhizospheric Bacterial Communities}

Our comparative genomic analysis of bacterial properties involved in plant growth promotion identified 28 out of 704 tested KOs that were significantly affected by parasitization (Fig. 3, Supplementary Table 3). We observed a reduction in abundance of 11 protein-encoding genes related to quorum sensing and signal transduction (ciaR, comA subfamily $\mathrm{C}$ and Narl, cqsS, glrK/qseE, glrR/qseF, hlyB/cyaB, narG, spo0A, srfAC/lchAC, and yajC) and an enrichment of four others (COX15, ftsY, PLD1_2, and spoOF). The genes involved in the degradation of xenobiotics $(\mathrm{dmpB} / \mathrm{xylE})$ and in the biosynthesis of flavonoids (E2.1.1.104) were less abundant in the rhizosphere of parasitized plants. On the other hand, six genes associated with antibiotics biosynthesis (adhE, aspC, cts4/prnC, fadB, frmA/ADH5/adhC, and paaF/ ech $A$ ), the $n r t D / c y n D$ gene involved in the nitrate/nitrite transport, and the $b g l B$ gene encoding for beta-glucosidase 


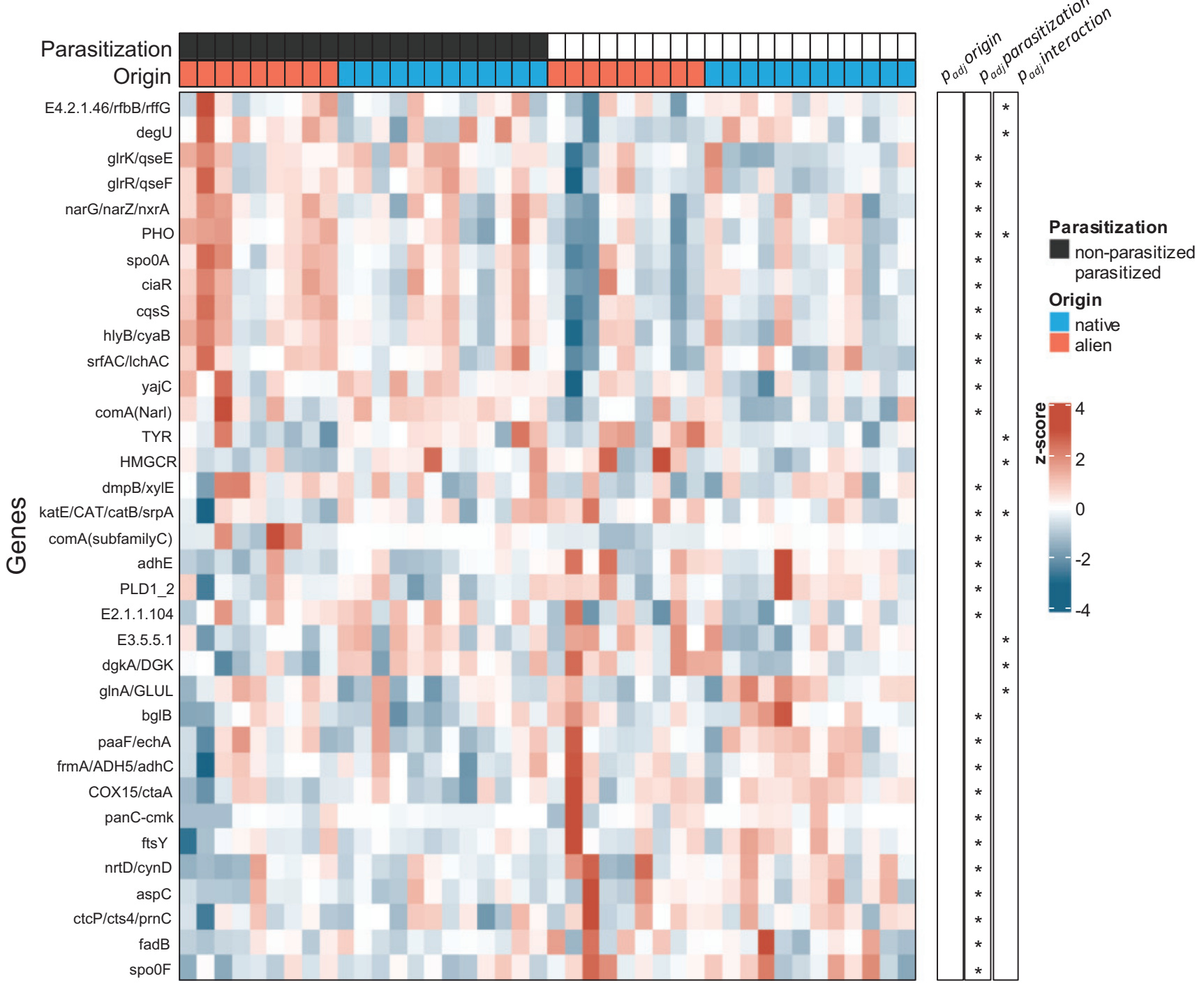

Fig. 3 Heat map of gene (KO) abundances related to different bacterial functions that are potentially relevant for plant growth. The color ramp refers to the scaled relative abundance ( $z$-score) of each gene after accounting for the host species effect (the host-species effect was removed by using the "removeBatchEffect" function from the limma R package

enzymes were more prevalent in the rhizosphere microbiome of parasitized plants.

\section{Effect of Host Origin on the Functional Composition of the Rhizosphere Bacterial Communities}

Differential abundance testing did not reveal significant differences in abundance of potentially plant growth relevant genes between rhizosphere bacterial communities of native and alien host plants. However, nine KOs were significantly affected by the interaction between parasitization and host origin (Fig. 3). In four cases, gene abundance was affected by parasitization only in aliens: the $\operatorname{deg} U$ gene (involved in quorum sensing) and the $\mathrm{PHO}$ gene (involved in inorganic
[53]). The annotations at the top of the figure provide information about parasitization (black for non-parasitized and white for parasitized host plants) and host origin (blue for native and red for alien plants species). Asterisks on the right side indicate the significance of the effect of host origin, parasitization, and their interaction on gene abundances

phosphate assimilation) were less abundant in parasitized alien plants, and the $d g k A / D G K$ and $k a t E / C A T / c a t B / s r p A$ genes (both involved in signal transduction) were more abundant in parasitized alien plants (Supplementary Fig. 6). In the five other cases, post hoc analyses revealed marginally significant differences between group means.

\section{KOs Associated with Nitrogen Metabolism}

The KOs involved in nitrogen metabolism could be assigned to six different reactions (Fig. 4). The total $\mathrm{KO}$ abundance of three of these reactions was lower in the rhizosphere of parasitized hosts (Fig. 4). These reactions were anaerobic ammonium oxidation $\left(F=7.52, p=0.009, p_{\text {adj }}=0.038\right)$, 

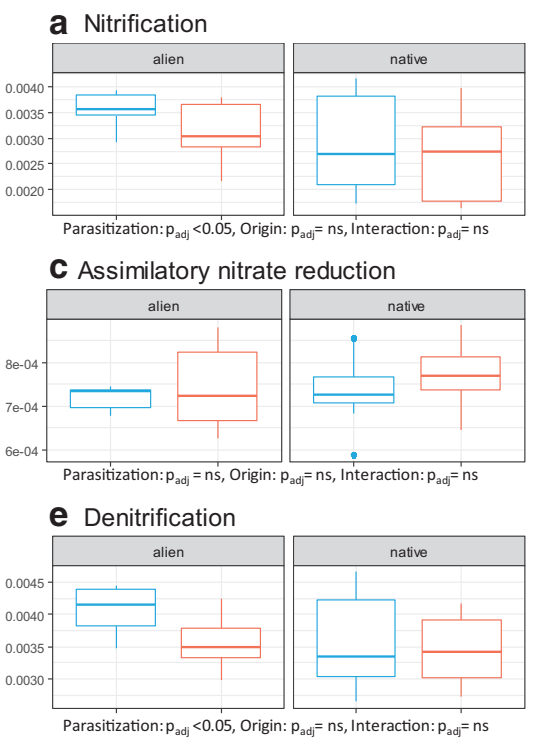

b Dissimilatory nitrate reduction

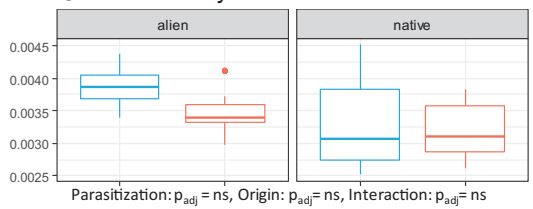

d Anaerobic ammonium oxidation

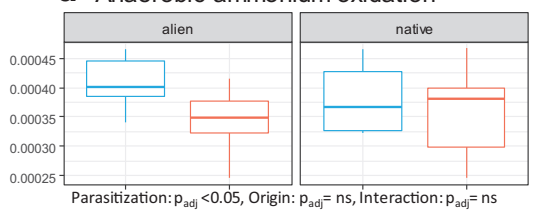

f Nitrogen fixation

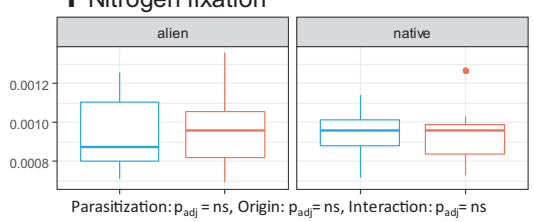

g

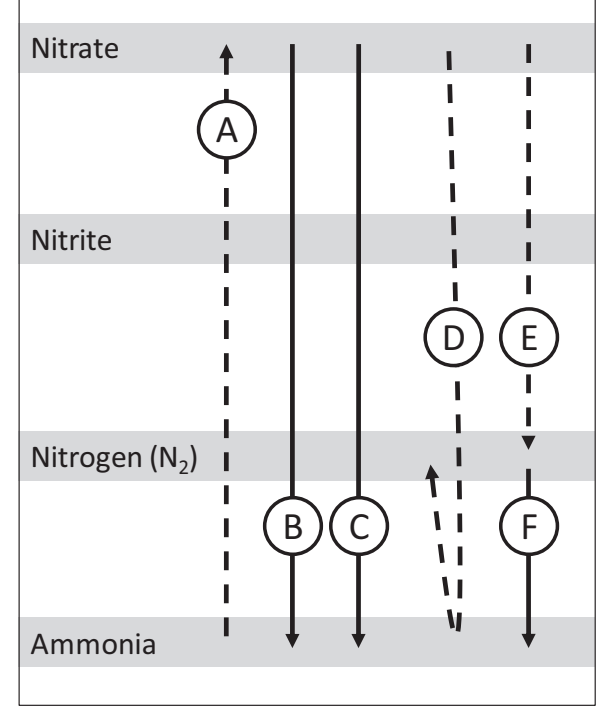

Fig. 4 Bacterial nitrogen metabolism as described by the six main reactions involved in $\mathrm{N}$ transformation, i.e., (a) nitrification, (b) dissimilatory nitrate reduction, (c) assimilatory nitrate reduction, (d) anaerobic ammonium oxidation, (e) denitrification, (f) nitrogen fixation nitrification, and (g) the schematic representation of the $\mathrm{N}$ cycle in the rhizosphere. Gray rectangles in the background stand for the different oxidation states of $\mathrm{N}$ that are found across the different reactions.
Values on the $y$-axis refer to the estimated gene abundance. The blue color corresponds to the non-parasitized host, and the red color corresponds to the parasitized host. The letters on the arrows in G refer to the corresponding reactions (panel A to F). Dashed arrows correspond to the reactions that are negatively affected by Cuscuta parasitism $\left(p_{\text {adj }}<\right.$ $0.05)$

and, as a consequence, the bacterial and fungal diversity were not affected by plant parasitization.

The microbial community shift due to parasitization is caused by numerous phylotypes belonging to at least 20 bacterial and 8 fungal phyla. Among the bacteria, plant parasitization induced a taxonomic shift inside the Planctomycetes phylum, favored a greater number of Acidobacteria phylotypes, and reduced the overall Verrucomicrobia prevalence. These three phyla have been identified to be among the most active bacterial phyla assimilating plant-derived carbon in the rhizosphere of Oilseed rape [54]. This suggests that the observed taxonomic replacement may attest to a deep modification in plant carbon supply and, at least, in the rhizosphere carbon cycle. This might reflect that the uptake of sugars by the parasite changes the carbon availability in the rhizosphere of the hosts.

Our results suggest that the fungi were more sensitive to parasitization compared with bacteria. This was unexpected because numerous studies have reported that bacteria are more sensitive to changes in chemical, physical, and geological properties in rhizosphere soil than fungi [55-57]. Although our study is one of the first to explore the modification of the microbiome induced by plant parasitization, a lot of work has been conducted about how the phloem physiology influences the rate of water and carbon transfer to the soil and how this affects rhizosphere microbiota [58]. It has been shown that bacteria predominate in the early stages of organic matter decomposition (decomposition of the labile fraction of the
The microbial community shift that we found in the rhizosphere of the seven plant species was due to changes in the relative abundance of numerous taxa. About $7 \%$ of bacterial phylotypes and about $11 \%$ of fungal phylotypes were sensitive to parasitization. Similar numbers of rhizospheric phylotypes were either favored or restrained by plant parasitization,

\section{Parasitization Induced a Shift in Host Rhizosphere Microbiome}


organic matter), and that fungi play a key role in the later stages by decomposing the most recalcitrant compounds [59-61]. The greater shift in fungal communities could then be partly explained by the fungal contribution to metabolization of plant-derived carbon. Numerous fungal taxa belonging to Ascomycota were less prevalent when plants were parasitized. Possibly, this is because Ascomycota, which was the most abundant phylum in our study (37\%), are mainly considered to be cellulose decomposers or sugar fungi [62], substrates that might be reduced by the parasitization.

In addition to affecting microbiota involved in $\mathrm{C}$ cycling, plant parasitization may also select specific microbial taxa due to their ability to face particular stressors. For example, we found that fewer Chytridiomycota phylotypes were downregulated by plant parasitization. The zoosporic form of chytrids might confer them an advantage when facing osmotic stress [63], which could be induced by a reduction of root water exudation caused by plant parasitization. Another example is a phylotype of the genus Anaeromyxobacter, which we found to be positively associated with parasitized plants. This genus consists of myxobacterial species capable of using many oxidized organic and inorganic compounds as electron acceptors, enabling them to face harsh environmental conditions [64-66].

Given the overwhelming amount of undescribed soil microbial diversity [67], it is still difficult to confidently assign microbial clades into groups with particular life history strategies. In conclusion, our results taken together point at two mutually non-exclusive scenarios that could explain the observed community shift due to parasitization: (i) a shift from less to more recalcitrant $\mathrm{C}$ compounds in the rhizosphere of the host plant or (ii) a selection pressure in favor of taxa able to face environmental stresses.

\section{Potential Implications of Microbiome Modification for the Plant}

Shifts in the prevalence of certain phyla or taxa within phyla with known functions suggest that some of the changes in the microbial community in response to parasitization may affect plant performance. For example, parasitization decreased the abundance of identified arbuscular mycorrhizal fungi (AMF), which generally improves nutrition, as well as stress resistance and tolerance of plants. AMF may also affect seed germination, primary root development, and colonization of host plants of certain Cuscuta species [68-71], but to date, AMF effects on Cuscuta australis have not been reported. If the decrease in AMF abundance in the rhizosphere of parasitized host plant attests to a reduction in AMF mycelium, it could indicate a severe reduction in nutrient assimilation of the hostparasite complex. On the other hand, two of the three fungal species (Thanatephorus cucumeris and Gibberella sp.) that we found to be mainly associated with parasitized plants have been described in the literature as plant pathogens, and the third one, the ectomycorrhizal Entoloma sp., as a pathotroph and potential plant parasite [38]. So, the functional composition of the fungal community shifted with parasitization from beneficial fungal species to pathogenic fungal species. Parasitization may thus indirectly (through changes in the rhizosphere fungal communities) decrease the growth of the host plants.

We also found that the abundance of certain microbial genes involved in rhizosphere processes that are likely to promote plant growth was impacted by the parasitization and the parasitization-by-host interaction, but not by the host origin. It should be noted, however, that the presence of genes in a metagenome does not necessarily mean that these genes are being expressed. Nevertheless, Ofek-Lalzar et al. [72] combined both metagenomics (functional potential) and metatranscriptomics (functional expression), and showed that a large proportion of the genes involved in plant growth promotion was indeed expressed. Thus, we can postulate that at least some of the genes affected by plant parasitization in our study may induce shifts in microbe-microbe and microbeplant interactions.

We found that a dozen genes involved in quorum sensing and signal transduction were affected, two-third of which were downregulated. Quorum sensing is a form of cell densitydependent population behavior, in which the production, detection, and response to specific small molecules regulate gene expression of the bacteria, favoring harmonized and optimal microbial metabolism [73]. Changes in quorum sensing may have important implications both for microbe-microbe and plant-microbe interactions since it has been shown to control essential processes, such as the regulation of virulence-trait expression, sporulation, biofilm formation, extracellular enzyme production, and exopolysaccharide production [74-77].

Parasitization by Cuscuta also impacted the abundance of three genes important for bacterial sporulation, Spo0A, SpoOF, and $f t s$. The response regulator $S p o 0 A$ is the master protein for entry into sporulation, and is only active in its phosphorylated form [78]. The accumulation of the phosphorylated form is governed by a regulatory cascade network involving the relay protein $S p o 0 F$. The third gene, fts $Y$, plays a pivotal role in assembling proteins onto the coat layer during spore morphogenesis [79]. Therefore, despite the downregulation of SpoOA genes, the observed increases in $\mathrm{SpoOF}$ and fts $Y$ suggest a possible increase in spore-forming bacteria in the rhizosphere of parasitized plants. By forming spores, bacteria enter a dormant state that allows them to survive adverse environmental conditions (reviewed in [80]). So, likely, the parasite-driven changes in root growth and turnover, and root exudation patterns imposed environmental stresses that induced sporulation of bacteria.

In our study, parasitization upregulated the number of genes involved in antibiotics production. This were 
particularly the gene $c t s 4 / p r n C$, which encodes for enzymes involved in tetracycline and staurosporine biosynthesis, and the $r f b B / r f f G$ gene, which plays a role in the production of vancomycin, streptomycin, and validomycin. Antibiotics have long been assumed to yield a competitive advantage to the bacteria that produce them by direct suppression of their competitors, particularly in resource-limited environments [81]. However, at subinhibitory concentrations, antibiotics exhibit a diversity of other roles in the life history of the bacteria that produce them (e.g., in shaping the outcomes of multitrophic interactions, reviewed in [81]). Within the context of plantassociated microorganisms, antibiotics produced by bacteria have been commonly shown to control plant pathogens, although they can also cause plant diseases [82-84]. Here, we did not observe the consequences of such changes on the parasite/host fitness. Together, the potential inhibition of quorum sensing and the increase in production of antibiotics in the rhizosphere of parasitized plants suggest that Cuscuta parasitism favors competitive over cooperative bacterial behaviors.

In our study, we paid particular attention to microbes involved in nitrogen metabolism, because $\mathrm{N}$ availability is a major factor driving plant growth. The downregulation of nitrification, anaerobic ammonium oxidation, and denitrification in the rhizosphere of parasitized plants is likely to result in a reduction of nitrogen $\left(\mathrm{N}_{2}\right)$, and an increase of ammonium and nitrate pools in the soil. Unlike $\mathrm{N}_{2}$, nitrate and ammonium are $\mathrm{N}$ molecules that can be directly taken up and metabolized by most plants [85]. Denitrification inhibition has been suggested to be a niche construction mechanism in plants of Fallopia species, which leads to the accumulation of soil nitrate and, in turn, can lead to an increase in plant biomass. Rajan et al. [86] found increased expression of genes associated with the transport of nitrate and ammonia in Cuscuta pentagona at the haustorial stage, and Jeschke and Hilpert [18] showed that plant parasitization by Cuscuta reflexa induced simultaneously an inhibition of nitrate assimilation in the host roots and an increase in nitrate uptake. This suggests that the rhizosphere functional modification implied by our results could be beneficial to Cuscuta without any benefit to its host. This would be in line with findings of Gao et al. [87], who also found that the addition of $\mathrm{NH}_{4} \mathrm{NO}_{3}$ to the soil of soybean increased the biomass of $C$. australis parasitizing the soybean but not the soybean biomass.

\section{Alien Plants Could Be More Vulnerable to Parasitization}

We found some differences in the composition of the rhizosphere microbial communities of native and alien plants. Several other recent studies have also highlighted significant differences between native and alien plant microbiomes [88-90]. These differences might affect the invasiveness of alien plants both positively and negatively [91]. We found a higher Acidobacteria to Proteobacteria ratio, which is known to attest to high nutrient conditions [92], in the rhizosphere of invasive alien host plants than in that of native host plants. Our results may either indicate a greater nutrient supply from alien plants than from native plants to the rhizosphere, or that invasive alien plants preferably grew in the high nutrient patches of our study area. Indeed, many invasive alien plants are opportunists that take advantage of spatial or temporal nutrient pulses [93-95].

A recent meta-analysis by Zhang et al. [96] suggested that plant litter of invasive alien plants increased decomposers' abundance in the litter compartment $(+16 \%$ in bacterial biomass) and promoted nutrient release. However, they also found that roots of invasive alien plants had less bacterial biomass in the rhizosphere $(-12 \%)$, but more AMF biomass $(+36 \%)$, the latter suggesting an increased nutrientacquisition capacity. In our study, we showed that parasitization induced stronger changes of fungal communities in the rhizosphere of native plants than in the rhizosphere of alien plants. This could reflect a greater ability of alien plants to maintain their nutrient acquisition capacity via fungal mycorrhiza. Zhang et al. [96] hypothesized that the litter- and rootbased loops are coupled to generate positive feedback of alien invaders on soil systems by stimulating nutrient cycling, which in turn increases alien plant fitness. This, however, might differ in the presence of Cuscuta, because parasitization is known to severely affect the nutrient release of the host plant ( $\sim 40 \%$ biomass loss reported with parasitization of the alien weed Humulus scandens, [97]). This is likely to considerably reduce litter supply and to disrupt the mechanism by which alien plants benefit from the surrounding microbiota.

Our results further showed that the abundance of the $\mathrm{PHO}$ gene (encoding for acid phosphatase, which permits inorganic phosphate assimilation) was particularly reduced in the rhizosphere of parasitized alien plants, whereas it was not affected by parasitization in the rhizosphere of native plants. Phosphate is not only a plant growth-limiting factor [98], it is also required for DNA replication and transcription of fast-growing bacteria that supply the plants with essential nutrients [99, 100]. By maintaining fungal interactions and altering fast growing decomposers, it is likely that Cuscuta parasitization of alien plants affects the mechanism by which alien plants benefit from their surrounding microbiota. This could then be a part of the explanation of the observed greater susceptibility of some alien host plants to novel native generalist parasitic plants than native host plants $[27,97,101]$.

\section{Conclusion}

Our study was the first to explore and to quantify the shift in microbial communities induced by plant parasitization in the rhizosphere of host plants. The use of metagenomic analysis 
of fungi and bacteria showed that Cuscuta parasitism induced variation in the taxonomic and the functional microbial diversity of the rhizosphere. These may attest to a deep modification in the rhizosphere $\mathrm{C}$ cycle and could lead to negative feedbacks to the plant. However, this also clearly depends on additional factors such as the identity of the host plant species and its origin. Further studies focusing of the feedbacks of such microbial changes on the fitness of the hostparasite complex are required to determine the physiological costs and benefits to the plants. Moreover, controlled studies in which plants are experimentally parasitized would be needed to examine the effects on plant growth and root exudation. Finally, further studies on plant-soil feedback would allow clarifying how the soil microbiomes collected under infected and non-infected plants affect plant growth.

Funding Information This project has been realized with the financial support of the Chinese National Key Research and Development Program (No. 2016YFC1201100), the Inter-governmental S\&T Cooperation Proposal between Bulgaria and China (No. 15-2), and the National Natural Science Foundation of China (No. 30800133).

\section{References}

1. Press MC, Phoenix GK (2005) Impacts of parasitic plants on natural communities. New Phytol 166:737-751. https://doi.org/ 10.1111/j.1469-8137.2005.01358.x

2. Yoshida S, Cui S, Ichihashi Y, Shirasu K (2016) The haustorium, a specialized invasive organ in parasitic plants. Annu Rev Plant Biol 67:643-667

3. Bardgett RD, Smith RS, Shiel RS, Peacock S, Simkin JM, Quirk H, Hobbs PJ (2006) Parasitic plants indirectly regulate belowground properties in grassland ecosystems. Nature 439:969-972

4. Gressel J, Hanafi A, Head G, Marasas W, Obilana AB, Ochanda J, Souissi T, Tzotzos G (2004) Major heretofore intractable biotic constraints to African food security that may be amenable to novel biotechnological solutions. Crop Prot 23:661-689. https://doi.org/ 10.1016/j.cropro.2003.11.014

5. Yoder JI, Scholes JD (2010) Host plant resistance to parasitic weeds; recent progress and bottlenecks. Curr Opin Plant Biol 13: 478-484. https://doi.org/10.1016/j.pbi.2010.04.011

6. Saric-Krsmanovic MM, Bozic DM, Radivojevic LM, Umiljendic JSG, Vrbnicanin SP (2017) Effect of Cuscuta campestris parasitism on the physiological and anatomical changes in untreated and herbicide-treated sugar beet. J Environ Sci Health Part B 52:812 816. https://doi.org/10.1080/03601234.2017.1356167

7. Hibberd JM, Jeschke WD (2001) Solute flux into parasitic plants. J Exp Bot 52:2043-2049. https://doi.org/10.1093/jexbot/52.363. 2043

8. Koskela, Salonen, Mutikainen (2000) Local adaptation of a holoparasitic plant, Cuscuta europaea: variation among populations. J Evol Biol 13:749-755. https://doi.org/10.1046/j.14209101.2000.00226.x

9. Aukema JE (2003) Vectors, viscin, and Viscaceae: mistletoes as parasites, mutualists, and resources. Front Ecol Environ 1:212219. https://doi.org/10.1890/1540-9295(2003)001[0212: VVAVMA]2.0.CO;2

10. Hunter P (2016) Plant microbiomes and sustainable agriculture: deciphering the plant microbiome and its role in nutrient supply and plant immunity has great potential to reduce the use of fertilizers and biocides in agriculture. Embo Rep 17:1696-1699. https://doi.org/10.15252/embr.201643476

11. Chialva M, Zhou Y, Spadaro D, Bonfante P (2018) Not only priming: soil microbiota may protect tomato from root pathogens. Plant Signal Behav 13:e1464855. https://doi.org/10.1080/ 15592324.2018.1464855

12. Egamberdieva D, Wirth SJ, Alqarawi AA, Abd_Allah EF, Hashem A (2017) Phytohormones and beneficial microbes: essential components for plants to balance stress and fitness. Front Microbiol 8:2104. https://doi.org/10.3389/fmicb.2017.02104

13. Pii Y, Mimmo T, Tomasi N, Terzano R, Cesco S, Crecchio C (2015) Microbial interactions in the rhizosphere: beneficial influences of plant growth-promoting rhizobacteria on nutrient acquisition process. A review. Biol Fertil Soils 51:403-415. https://doi. org/10.1007/s00374-015-0996-1

14. Feng H, Zhang N, Fu R, Liu Y, Krell T, du W, Shao J, Shen Q, Zhang R (2018) Recognition of dominant attractants by key chemoreceptors mediates recruitment of plant growth-promoting rhizobacteria: key determinants for rhizosphere chemotaxis. Environ Microbiol 21:402-415. https://doi.org/10.1111/14622920.14472

15. Gifford I, Battenberg K, Vaniya A, Wilson A, Tian L, Fiehn O, Berry AM (2018) Distinctive patterns of flavonoid biosynthesis in roots and nodules of Datisca glomerata and Medicago spp. Revealed by metabolomic and gene expression profiles. Front Plant Sci 9. https://doi.org/10.3389/fpls.2018.01463

16. López-Ráez JA, Shirasu K, Foo E (2017) Strigolactones in plant interactions with beneficial and detrimental organisms: the Yin and Yang. Trends Plant Sci 22:527-537. https://doi.org/10.1016/ j.tplants.2017.03.011

17. Jeschke WD, Bäumel P, Räth N, Czygan FC, Proksch P (1994) Modelling of the flows and partitioning of carbon and nitrogen in the holoparasite Cuscuta reflexa Roxb. and its host Lupinus albus L.II. Flows between host and parasite and within the parasitized host. J Exp Bot 45:801-812. https://doi.org/10.1093/jxb/45.6.801

18. Jeschke WD, Hilpert A (1997) Sink-stimulated photosynthesis and sink-dependent increase in nitrate uptake: nitrogen and carbon relations of the parasitic association Cuscuta reflexa-Ricinus communis. Plant Cell Environ 20:47-56. https://doi.org/10.1046/ j.1365-3040.1997.d01-2.x

19. Delavault P, Montiel G, Brun G, et al (2017) Chapter three communication between host plants and parasitic plants. In: Becard G (ed) Advances in Botanical Research. Academic Press, pp 55-82

20. Dong M, Lu J, Zhang W et al (2006) Canada goldenrod ( $\{\backslash \mathrm{sl}$ Solidago canadensis $\}$ ): an invasive alien weed rapidly spreading in China. Acta Phytotaxon Sin 44:72-85

21. Shen H, Ye W, Hong L, Huang H, Wang Z, Deng X, Yang Q, Xu Z (2006) Progress in parasitic plant biology: host selection and nutrient transfer. Plant Biol 8:175-185. https://doi.org/10.1055/s2006-923796

22. Yu H, Yu F-H, Miao S-L, Dong M (2008) Holoparasitic Cuscuta campestris suppresses invasive Mikania micrantha and contributes to native community recovery. Biol Conserv 141:2653-2661. https://doi.org/10.1016/j.biocon.2008.08.002

23. Prider J, Watling J, Facelli JM (2009) Impacts of a native parasitic plant on an introduced and a native host species: implications for the control of an invasive weed. Ann Bot 103:107-115. https:// doi.org/10.1093/aob/men214

24. Baráth K (2012) A new method for evaluating host preference of Cuscuta species. Acta Bot Hungar 54:219-234

25. Liao C, Peng R, Luo Y, Zhou X, Wu X, Fang C, Chen J, Li B (2008) Altered ecosystem carbon and nitrogen cycles by plant invasion: a meta-analysis. New Phytol 177:706-714. https://doi. org/10.1111/j.1469-8137.2007.02290.x 
26. Karger DN, Conrad O, Boehner J et al (2017) Data descriptor: climatologies at high resolution for the earth's land surface areas. Sci Data 4:170122. https://doi.org/10.1038/sdata.2017.122

27. Yu H, Liu J, He W-M, Miao SL, Dong M (2011) Cuscuta australis restrains three exotic invasive plants and benefits native species. Biol Invasions 13:747-756

28. Le Q-V, Tennakoon KU, Metali F et al (2015) Impact of Cuscuta australis infection on the photosynthesis of the invasive host, Mikania micrantha, under drought condition. Weed Biol Manag 15:138-146

29. Weber E, Sun S-G, Li B (2008) Invasive alien plants in China: diversity and ecological insights. Biol Invasions 10:1411-1429. https://doi.org/10.1007/s10530-008-9216-3

30. Klindworth A, Pruesse E, Schweer T, Peplies J, Quast C, Horn M, Glöckner FO (2013) Evaluation of general 16S ribosomal RNA gene PCR primers for classical and next-generation sequencingbased diversity studies. Nucleic Acids Res 41:e1-e1

31. Orgiazzi A, Lumini E, Nilsson RH, Girlanda M, Vizzini A, Bonfante P, Bianciotto V (2012) Unravelling soil fungal communities from different Mediterranean land-use backgrounds. PLoS One 7:e34847

32. Callahan BJ, Sankaran K, Fukuyama JA, et al (2016) Bioconductor workflow for microbiome data analysis: from raw reads to community analyses. F1000Research 5:

33. Callahan BJ, McMurdie PJ, Holmes SP (2017) Exact sequence variants should replace operational taxonomic units in markergene data analysis. ISME J 11:2639-2643

34. Martin M (2011) Cutadapt removes adapter sequences from highthroughput sequencing reads. EMBnet.Journal 17:10-12. https:// doi.org/10.14806/ej.17.1.200

35. UNITE Community (2017) UNITE general FASTA release. Version 01.12.2017

36. Quast C, Pruesse E, Yilmaz P, Gerken J, Schweer T, Yarza P, Peplies J, Glöckner FO (2013) The SILVA ribosomal RNA gene database project: improved data processing and web-based tools. Nucleic Acids Res 41:D590-D596. https://doi.org/10.1093/nar/ gks 1219

37. Weiss S, Xu ZZ, Peddada S, Amir A, Bittinger K, Gonzalez A, Lozupone C, Zaneveld JR, Vázquez-Baeza Y, Birmingham A, Hyde ER, Knight R (2017) Normalization and microbial differential abundance strategies depend upon data characteristics. Microbiome 5:27. https://doi.org/10.1186/s40168-017-0237-y

38. Nguyen NH, Song Z, Bates ST, Branco S, Tedersoo L, Menke J, Schilling JS, Kennedy PG (2016) FUNGuild: an open annotation tool for parsing fungal community datasets by ecological guild. Fungal Ecol 20:241-248

39. Aßhauer KP, Wemheuer B, Daniel R, Meinicke P (2015) Tax4Fun: predicting functional profiles from metagenomic 16S rRNA data. Bioinformatics 31:2882-2884. https://doi.org/10. 1093/bioinformatics/btv287

40. R Core Team (2018). R: a language and environment for statistical computing

41. Bates D, Maechler M, Bolker BM, Walker SC (2015) Fitting linear mixed-effects models using lme4. J Stat Softw 67:1-48

42. Dixon P (2003) VEGAN, a package of R functions for community ecology. J Veg Sci 14:927-930. https://doi.org/10.1111/j.16541103.2003.tb02228.x

43. Zhang X, Pei Y-F, Zhang L, Guo B, Pendegraft AH, Zhuang W, Yi $\mathrm{N}$ (2018) Negative binomial mixed models for analyzing longitudinal microbiome data. Front Microbiol 9. https://doi.org/10.3389/ fmicb.2018.01683

44. Kanehisa M, Furumichi M, Tanabe M, Sato Y, Morishima K (2017) KEGG: new perspectives on genomes, pathways, diseases and drugs. Nucleic Acids Res 45:D353-D361. https://doi.org/10. 1093/nar/gkw1092
45. Benjamini Y, Hochberg Y (1995) Controlling the false discovery rate: a practical and powerful approach to multiple testing. J R Stat Soc Ser B Methodol 57:289-300

46. Lenth RV (2016) Least-squares means: the R package lsmeans. J Stat Softw 69:1-33. https://doi.org/10.18637/jss.v069.i01

47. Dufrêne M, Legendre P (1997) Species assemblages and indicator species: the need for a flexible asymmetrical approach. Ecol Monogr 67:345-366

48. De Cáceres M, Legendre P, Moretti M (2010) Improving indicator species analysis by combining groups of sites. Oikos 119:1674 1684. https://doi.org/10.1111/j.1600-0706.2010.18334.x

49. Wickham H (2009) ggplot2: elegant graphics for data analysis. Springer-Verlag, New York

50. Stockinger H, Krüger M, Schüßler A (2010) DNA barcoding of arbuscular mycorrhizal fungi. New Phytol 187:461-474. https:// doi.org/10.1111/j.1469-8137.2010.03262.x

51. Weber SE, Diez JM, Andrews LV, Goulden ML, Aronson EL, Allen MF (2019) Responses of arbuscular mycorrhizal fungi to multiple coinciding global change drivers. Fungal Ecol 40:62-71. https://doi.org/10.1016/j.funeco.2018.11.008

52. Fletcher A (2008) Fungal families of the world. By P. F. Cannon and P. M. Kirk. 2007. Wallingford, Oxfordshire, UK: CAB international. $\mathrm{Pp}$ xiii, 456, numerous colour plates and figures, $215 \times 300 \mathrm{~mm}$ (A4). ISBN 978085199827 5, hardback. Available from CABI, Nosworthy Way, Wallingford, Oxfordshire OX10 8DE, email: cabi@cabi.org, website: www.cabi.org. Price $£ 75$. Lichenologist 40:463-463. https://doi. org/10.1017/S0024282908009158

53. Ritchie ME, Phipson B, Wu D, Hu Y, Law CW, Shi W, Smyth GK (2015) Limma powers differential expression analyses for RNAsequencing and microarray studies. Nucleic Acids Res 43:e47e47

54. Gkarmiri K, Mahmood S, Ekblad A et al (2017) Identifying the active microbiome associated with roots and rhizosphere soil of oilseed rape. Appl Environ Microbiol 83:UNSP e01938-UNSP e01917. https://doi.org/10.1128/AEM.01938-17

55. Jansen E, Michels M, van Til M, Doelman P (1994) Effects of heavy metals in soil on microbial diversity and activity as shown by the sensitivity-resistance index, an ecologically relevant parameter. Biol Fertil Soils 17:177-184. https://doi.org/10.1007/ BF00336319

56. Germida JJ, Siciliano SD, Renato de Freitas J, Seib AM (1998) Diversity of root-associated bacteria associated with field-grown canola (Brassica napus L.) and wheat (Triticum aestivum L.). FEMS Microbiol Ecol 26:43-50. https://doi.org/10.1016/S01686496(98)00020-8

57. Grządziel J, Gałązka A (2018) Microplot long-term experiment reveals strong soil type influence on bacteria composition and its functional diversity. Appl Soil Ecol 124:117-123. https://doi.org/ 10.1016/j.apsoil.2017.10.033

58. Savage JA, Clearwater MJ, Haines DF, Klein T, Mencuccini M, Sevanto S, Turgeon R, Zhang C (2016) Allocation, stress tolerance and carbon transport in plants: how does phloem physiology affect plant ecology? Plant Cell Environ 39:709-725. https://doi. org/10.1111/pce. 12602

59. Romaní AM, Fischer H, Mille-Lindblom C, Tranvik LJ (2006) Interactions of bacteria and fungi on decomposing litter: differential extracellular enzyme activities. Ecology 87:2559-2569

60. van der Wal A, Geydan TD, Kuyper TW, de Boer W (2013) A thready affair: linking fungal diversity and community dynamics to terrestrial decomposition processes. FEMS Microbiol Rev 37: 477-494. https://doi.org/10.1111/1574-6976.12001

61. Berg B (2014) Decomposition patterns for foliar litter - a theory for influencing factors. Soil Biol Biochem 78:222-232. https:// doi.org/10.1016/j.soilbio.2014.08.005 
62. Schneider T, Keiblinger KM, Schmid E, Sterflinger-Gleixner K, Ellersdorfer G, Roschitzki B, Richter A, Eberl L, ZechmeisterBoltenstern S, Riedel K (2012) Who is who in litter decomposition? Metaproteomics reveals major microbial players and their biogeochemical functions. ISME J 6:1749-1762. https://doi.org/ 10.1038/ismej.2012.11

63. Brannelly LA, Berger L, Marrantelli G, Skerratt LF (2015) Low humidity is a failed treatment option for chytridiomycosis in the critically endangered southern corroboree frog. Wildl Res 42:44 49. https://doi.org/10.1071/WR14097

64. Onley JR, Ahsan S, Sanford RA, Loeffler FE (2018) Denitrification by Anaeromyxobacter dehalogenans, a common soil bacterium lacking the nitrite reductase genes nirS and nirK. Appl Environ Microbiol 84:UNSP e01985-UNSP e01917. https://doi.org/10.1128/AEM.01985-17

65. Chao T-C, Kalinowski J, Nyalwidhe J, Hansmeier N (2010) Comprehensive proteome profiling of the $\mathrm{Fe}(\mathrm{III})$-reducing myxobacterium Anaeromyxobacter dehalogenans 2CP-C during growth with fumarate and ferric citrate. Proteomics 10:16731684. https://doi.org/10.1002/pmic.200900687

66. Sanford RA, Cole JR, Tiedje JM (2002) Characterization and description of Anaeromyxobacter dehalogenans gen. nov., sp. nov., an aryl-halorespiring facultative anaerobic myxobacterium. Appl Environ Microbiol 68:893-900. https://doi.org/10.1128/AEM.68. 2.893-900.2002

67. Locey KJ, Lennon JT (2016) Scaling laws predict global microbial diversity. Proc Natl Acad Sci U S A 113:5970-5975. https:// doi.org/10.1073/pnas.1521291113

68. Sanders IR, Koide RT, Shumway DL (1993) Mycorrhizal stimulation of plant parasitism. Can J Bot 71:1143-1146. https://doi. org/10.1139/b93-134

69. Behdarvandi B, Guinel FC, Costea M (2015) Differential effects of ephemeral colonization by arbuscular mycorrhizal fungi in two Cuscuta species with different ecology. Mycorrhiza 25:573-585. https://doi.org/10.1007/s00572-015-0632-9

70. Khalid AN, Iqbal SH (1995) Mycotrophy in a vascular stem parasite Cuscuta reflexa. Mycorrhiza 6:69-71. https://doi.org/10. 1007/s005720050109

71. Benvenuti S, Dinelli G, Bonetti A, Catizone P (2005) Germination ecology, emergence and host detection in Cuscuta campestris. Weed Res 45:270-278. https://doi.org/10.1111/j.1365-3180. 2005.00460.x

72. Ofek-Lalzar M, Sela N, Goldman-Voronov M, Green SJ, Hadar Y, Minz D (2014) Niche and host-associated functional signatures of the root surface microbiome. Nat Commun 5:4950. https://doi.org/ 10.1038/ncomms5950

73. Evans KC, Benomar S, Camuy-Vélez LA, Nasseri EB, Wang X, Neuenswander B, Chandler JR (2018) Quorum-sensing control of antibiotic resistance stabilizes cooperation in Chromobacterium violaceum. ISME J 12:1263-1272. https://doi.org/10.1038/ s41396-018-0047-7

74. Loh J, Pierson EA, Pierson LS et al (2002) Quorum sensing in plant-associated bacteria. Curr Opin Plant Biol 5:285-290. https:// doi.org/10.1016/S1369-5266(02)00274-1

75. Shi S, Nuccio EE, Shi ZJ, He Z, Zhou J, Firestone MK (2016) The interconnected rhizosphere: high network complexity dominates rhizosphere assemblages. Ecol Lett 19:926-936. https://doi.org/ 10.1111/ele. 12630

76. Jung BK, Khan AR, Hong S-J, Park GS, Park YJ, Kim HJ, Jeon HJ, Khan MA, Waqas M, Lee IJ, Lee SE, Shin JH (2017) Quorum sensing activity of the plant growth-promoting rhizobacterium $<$ emphasis type $=$ "italic" $>$ Serratia glossinae $</$ emphasis $>$ GS2 isolated from the sesame (<emphasis type="italic">Sesamum indicum</emphasis> L.) rhizosphere. Ann Microbiol 67:623632. https://doi.org/10.1007/s13213-017-1291-1
77. DeAngelis KM, Lindow SE, Firestone MK (2008) Bacterial quorum sensing and nitrogen cycling in rhizosphere soil. FEMS Microbiol Ecol 66:197-207. https://doi.org/10.1111/j.1574-6941. 2008.00550.x

78. Predich M, Nair G, Smith I (1992) Bacillus subtilis early sporulation genes kinA, spo0F, and spo0A are transcribed by the RNA polymerase containing sigma $\mathrm{H}$. J Bacteriol 174:2771-2778. https://doi.org/10.1128/jb.174.9.2771-2778.1992

79. Kakeshita H, Takamatsu H, Amikura R, Nakamura K, Watabe K, Yamane K (2001) Effect of depletion of FtsY on spore morphology and the protein composition of the spore coat layer in Bacillus subtilis. FEMS Microbiol Lett 195:41-46. https://doi.org/10.1111/ j.1574-6968.2001.tb10495.x

80. Hutchison EA, Miller DA, Angert ER (2014) Sporulation in Bacteria: beyond the standard model. Microbiol Spectr 2. https:// doi.org/10.1128/microbiolspec.TBS-0013-2012

81. Raaijmakers JM, Mazzola M (2012) Diversity and natural functions of antibiotics produced by beneficial and plant pathogenic Bacteria. Annu Rev Phytopathol 50:403-424. https://doi.org/10. 1146/annurev-phyto-081211-172908

82. Joshi M, Rong X, Moll S, Kers J, Franco C, Loria R (2007) Streptomyces turgidiscabies secretes a novel virulence protein, Nec1, which facilitates infection. Mol Plant-Microbe Interact MPMI 20:599-608. https://doi.org/10.1094/MPMI-20-6-0599

83. Raaijmakers JM, de Bruijn I, de Kock MJD (2006) Cyclic lipopeptide production by plant-associated Pseudomonas spp.: diversity, activity, biosynthesis, and regulation. Mol Plant-Microbe Interact MPMI 19:699-710. https://doi.org/10.1094/MPMI-190699

84. Scholz-Schroeder BK, Hutchison ML, Grgurina I, Gross DC (2001) The contribution of syringopeptin and syringomycin to virulence of Pseudomonas syringae pv. syringae strain B301D on the basis of sypA and syrB1 biosynthesis mutant analysis. Mol Plant-Microbe Interact MPMI 14:336-348. https://doi.org/ 10.1094/MPMI.2001.14.3.336

85. Tegeder M, Masclaux-Daubresse C (2018) Source and sink mechanisms of nitrogen transport and use. New Phytol 217:35-53. https://doi.org/10.1111/nph.14876

86. Ranjan A, Ichihashi Y, Farhi M, Zumstein K, Townsley B, DavidSchwartz R, Sinha NR (2014) De novo assembly and characterization of the transcriptome of the parasitic weed dodder identifies genes associated with plant parasitism. Plant Physiol 166:11861199. https://doi.org/10.1104/pp.113.234864

87. Gao F-L, Che X-X, Yu F-H, Li J-M (2019) Cascading effects of nitrogen, rhizobia and parasitism via a host plant. Flora 251:6267. https://doi.org/10.1016/j.flora.2018.12.007

88. Anthony MA, Frey SD, Stinson KA (2017) Fungal community homogenization, shift in dominant trophic guild, and appearance of novel taxa with biotic invasion. Ecosphere 8:e01951. https:// doi.org/10.1002/ecs2.1951

89. Sielaff AC, Upton RN, Hofmockel KS et al (2018) Microbial community structure and functions differ between native and novel (exotic-dominated) grassland ecosystems in an 8-year experiment. Plant Soil 432:359-372. https://doi.org/10.1007/s11104018-3796-1

90. Toju H, Kurokawa H, Kenta T (2019) Factors influencing leafand root-associated communities of bacteria and fungi across 33 plant orders in a grassland. Front Microbiol 10. https://doi.org/10. 3389/fmicb.2019.00241

91. Dawson W, Schrama M (2016) Identifying the role of soil microbes in plant invasions. J Ecol 104:1211-1218

92. Smit E, Leeflang P, Gommans S, van den Broek J, van Mil S, Wernars K (2001) Diversity and seasonal fluctuations of the dominant members of the bacterial soil community in a wheat field as determined by cultivation and molecular methods. Appl Environ 
Microbiol 67:2284-2291. https://doi.org/10.1128/AEM.67.5. 2284-2291.2001

93. Dawson W, Fischer M, van Kleunen M (2012) Common and rare plant species respond differently to fertilisation and competition, whether they are alien or native. Ecol Lett 15:873-880. https://doi. org/10.1111/j.1461-0248.2012.01811.x

94. Liu Y, van Kleunen M (2017) Responses of common and rare aliens and natives to nutrient availability and fluctuations. J Ecol 105:1111-1122. https://doi.org/10.1111/1365-2745.12733

95. Parepa M, Fischer M, Bossdorf O (2013) Environmental variability promotes plant invasion. Nat Commun 4:1604. https://doi.org/ 10.1038/ncomms 2632

96. Zhang P, Li B, Wu J, Hu S (2019) Invasive plants differentially affect soil biota through litter and rhizosphere pathways: a metaanalysis. Ecol Lett 22:200-210. https://doi.org/10.1111/ele.13181

97. Wu A-P, Zhong W, Yuan J-R, Qi LY, Chen FL, Liang YS, He FF, Wang YH (2019) The factors affecting a native obligate parasite, Cuscuta australis, in selecting an exotic weed, Humulus scandens, as its host. Sci Rep 9:511. https://doi.org/10.1038/s41598-01836997-7
98. Oteino N, Lally RD, Kiwanuka S, Lloyd A, Ryan D, Germaine KJ, Dowling DN (2015) Plant growth promotion induced by phosphate solubilizing endophytic Pseudomonas isolates. Front Microbiol:6. https://doi.org/10.3389/fmicb.2015.00745

99. Elser JJ, Acharya K, Kyle M, Cotner J, Makino W, Markow T, Watts T, Hobbie S, Fagan W, Schade J, Hood J, Sterner RW (2003) Growth rate-stoichiometry couplings in diverse biota. Ecol Lett 6:936-943. https://doi.org/10.1046/j.1461-0248.2003. 00518.x

100. Elser JJ, Bracken MES, Cleland EE, Gruner DS, Harpole WS, Hillebrand H, Ngai JT, Seabloom EW, Shurin JB, Smith JE (2007) Global analysis of nitrogen and phosphorus limitation of primary producers in freshwater, marine and terrestrial ecosystems. Ecol Lett 10:1135-1142. https://doi.org/10.1111/j.14610248.2007.01113.x

101. Shen H, Ye W, Hong L, Cao H, Wang Z (2005) Influence of the obligate parasite Cuscuta campestris on growth and biomass allocation of its host Mikania micrantha. J Exp Bot 56:1277-1284. https://doi.org/10.1093/jxb/eri128 